\title{
Erratum to: Disagreeing with the (religious) skeptic
}

\section{Tomas Bogardus}

Published online: 4 June 2013

(C) Springer Science+Business Media Dordrecht 2013

\section{Erratum to: Int J Philos Relig DOI 10.1007/s11153-012-9342-9}

The original article was published with incorrect affiliation. The author's correct affiliation is provided below.

The online version of the original article can be found under doi:10.1007/s11153-012-9342-9.

\section{T. Bogardus $(\varangle)$}

Pepperdine University, 24255 Pacific Coast Highway, Malibu, CA 90263, USA

e-mail: tbogardus@gmail.com 